This item was submitted to Loughborough's Research Repository by the author.

Items in Figshare are protected by copyright, with all rights reserved, unless otherwise indicated.

\title{
Interdisciplinary content, contestations of knowledge and informational transparency in engineering curriculum
}

PLEASE CITE THE PUBLISHED VERSION

http://dx.doi.org/10.1080/13562517.2013.836089

\section{PUBLISHER}

(C) Taylor \& Francis Ltd

\section{VERSION}

AM (Accepted Manuscript)

\section{PUBLISHER STATEMENT}

This work is made available according to the conditions of the Creative Commons Attribution-NonCommercialNoDerivatives 4.0 International (CC BY-NC-ND 4.0) licence. Full details of this licence are available at: https://creativecommons.org/licenses/by-nc-nd/4.0/

\section{LICENCE}

CC BY-NC-ND 4.0

\section{REPOSITORY RECORD}

Barnard, Sarah, Tarek M. Hassan, Andrew R.J. Dainty, and Barbara Bagilhole. 2019. "Interdisciplinary Content, Contestations of Knowledge and Informational Transparency in Engineering Curriculum". figshare. https://hdl.handle.net/2134/17826. 


\section{Interdisciplinary Content, Contestations of Knowledge and Informational Transparency in Engineering Curriculum}

\section{Abstract:}

With the introduction of key information sets (KIS) for all university programmes in the UK from 2012, the character, content and delivery of university degrees may be increasingly used by potential students to differentiate between degree programmes. Therefore, developments in curricula and the relationship to the profession are of growing importance. In this paper we explore the role of programme content in prospective students' decision making and describe the prevalence of interdisciplinary content in civil engineering curricula. Following this we detail student perceptions of interdisciplinary content. It is found that; universities currently operate a varied approach to transparency regarding curriculum; students pay little attention to programme content before embarking on their chosen degree; and engineering students view interdisciplinary content in the curriculum with ambivalence, usually ascribing its necessity in the preparation for postuniversity employment.

Keywords: interdisciplinary content; engineering; curriculum; higher education.

\section{Introduction}

Current debates around the nature of academic boundaries and movements towards more interdisciplinary education in universities open up interesting avenues for investigations: not only in the academic and professional practice of disciplines, but in how these practices inform curriculum and impact on students themselves. With the planned compulsory introduction of key information sets (KIS) for all university programmes in the UK from 2012, the character, content and delivery of university degrees may be increasingly used by potential students to differentiate between degree programmes. KIS have been developed by the Higher Education Funding Council for England (HEFCE) in order to allow prospective students to access comparable information on fulltime or part time courses (HEFCE, 2012a), which is argued to enable students to make an informed choice about where and what to study (BBC, 2011). Universities are expected to collect and publish on their websites fifteen pieces of information ranging from student views on quality of the course, resources, feedback, salary and destination of graduates, tuition 
S. Barnard, T. Hassan, B. Bagilhole and A. Dainty (2013) Interdisciplinary Content, Contestations of Knowledge and Informational Transparency in Engineering Curriculum. Teaching in Higher Education, Vol. 18, Iss. 7, 2013. Available at: http://www.tandfonline.com/doi/full/10.1080/13562517.2013.836089\#

fees, accommodation costs, 'contact' hours per week and assessment methods. KIS represents a continuation of an emphasis on higher education performance indicators that can be used to hold institutions accountable for their performance, to inform budgetary allocations and assist in the targeting of policy initiatives, to inform student choices via institutional comparison and to support institutional self-publicity (Pugh et al., 2005: 21, see also HEFCE 2012b). Originally HEFCE performance indicators focused on the informational needs of government, policy makers and the institutions themselves (Pugh et al., 2005: 25), but now we can see a shift in emphasis towards providing information in relation to decisions about what and where to study. The concept of 'informed choice' is characterised by the development of multiple sources of information for prospective students, of which KIS represents but one. These include careers guidance in schools, university data publication, league tables, teaching quality audits, and the national student survey (NSS), Destinations of Leavers from Higher Education, (DLHE survey), web portals (DirectGov and UNISTATs), and also what may be termed 'private sector brokerage' (Davies, 2012).

Arguments for the development of information aimed at prospective students emphasise the impact informed choice will make on enhancing quality in higher education (HE). In this discourse there it is assumed that it is possible to observe performance, that visibility leads to transparency and that this then leads to improvement (Strathern, 2000). The possibility that transparency is different and may be at odds with enhancing quality is highlighted by Strathern (2000). Strathern (2000), utilising Tsoukas's (1997) work on the proliferation of audits and league tables, suggests that transparency of information is artificial and may actually conceal more than it reveals. Reasons for this include problems with performance indicators themselves (Strathern, 2000: 314); for example DLHE data, which informs part of KIS, has important data missing, small sample sizes and no control groups (Davies, 2012). In addition, indicators that students view as important, for example earnings after graduation - may be an inappropriate guide to earnings much later (Davies, 2012). This and other elements that appear in KIS are argued to be misleading and flawed; 'it does not appear that data on graduate salaries 
S. Barnard, T. Hassan, B. Bagilhole and A. Dainty (2013) Interdisciplinary Content, Contestations of Knowledge and Informational Transparency in Engineering Curriculum. Teaching in Higher Education, Vol. 18, Iss. 7, 2013. Available at: http://www.tandfonline.com/doi/full/10.1080/13562517.2013.836089\#

or student satisfaction can, in the majority of cases, provide students with a reliable basis for choice between alternative courses' (Davies, 2012: 272). Clearly there are issues around the validity and philosophical basis for increasing information that is aimed at prospective students.

This paper explores the availability of information for prospective students in $\mathrm{HE}$, developments in curriculum and the relationship to the professions via an examination of a single academic discipline - civil engineering. An historical overview of civil engineering in UK HE describes the particularities of the discipline and how its relationship with the profession has evolved. Following this we explore student perceptions of interdisciplinary content to develop an understanding of how the civil engineering discipline is interpreted and negotiated, and how innovations in content are experienced and perceived by students over the course of their study. This will enable a more nuanced understanding of how trends towards interdisciplinarity in HE and the profession impact on students themselves.

\section{Civil Engineering - evolution of a discipline}

In the early days of the UK engineering profession, skills and knowledge were acquired through an apprenticeship: the fundamentals of mathematical, scientific and design principles were learned 'on the job' and there was scepticism about the development of formal education. Even Brunel expressed caution with regards to theoretical training, which was a typical attitude during the early nineteenth century (Buchanan, 1989). However, during the industrial revolution influences from France underlined the need to train engineers more fully in scientific principles (Gregory, 1971). The Institution of Civil Engineers, founded in 1818, disseminated technical information and acted as the main network within the profession.

Early engineering education focused upon theoretical scientific principles that underpinned the more applied design approach students would apply in practice. Given that they would gain qualified status only once meeting the requirements of professional institutions, it was these that 'controlled 
S. Barnard, T. Hassan, B. Bagilhole and A. Dainty (2013) Interdisciplinary Content, Contestations of Knowledge and Informational Transparency in Engineering Curriculum. Teaching in Higher Education, Vol. 18, Iss. 7, 2013. Available at: http://www.tandfonline.com/doi/full/10.1080/13562517.2013.836089\#

professional practice and the entrance to it' (Gregory, 1971: 151). Formal engineering education consisted of pockets of activity in universities as there was a more general reluctance to embrace a substantial move towards a wide-scale education to replace the practical, work-based learning already established in the profession.It was concern about the nation's ability in the technical fields in comparison to those overseas - a response to the Paris Exhibition on 1867 - that brought the need for developments in engineering education to the fore (Buchanan, 1989). A key figure in the development of engineering science as a bridge between theory and practice is William John Macquorn Rankine, though 'the initial response to the Rankine system was cautious' (Buchanan, 1989: 170). It was during periods of development and expansion for the HE system that engineering education was able to gain a steadier foothold in the academy. Based on a compromise between the need for theoretical competence and the British engineering tradition of apprenticeship, engineering education was fully established in British universities by 1914 (Buchanan, 1989).

Severn (2009) argues that during the twentieth century there were important contextual changes in the HE sector that influenced the landscape of engineering education; the publication of the Robbins Report in 1963, which emphasised the expansion of $\mathrm{HE}$ and recommended that Colleges of Advance Technology should become universities; and Britain's accession to the European Economic Community (EEC) in 1973, which led to the introduction of the MEng (Masters of Engineering) course to UK engineering education and greater standardisation of course content in order to allow greater transferability across Europe (see also New Civil Engineer, 2009). Currently there are plans in universities in the UK to develop an interdisciplinary engineering curriculum, for example with business or environmental sciences, and innovative teaching and assessment methods, which form a continuation of earlier progress made in engineering education and reflect developments in HE more widely (Borrego and Cutler, 2010; Lueddeke, 2010).

\section{More recent developments - innovations in content and delivery}


The most frequently referred to concepts with regards to innovation in engineering curriculum are the introduction of interdisciplinary (or multidisciplinary) aspects to engineering courses (see for example, Cotgrave, 2005; Harrison et al., 2007; Ivins, 2007; Markes, 2006; Skates, 2003; Spinks et al, 2007), although these terms are not interchangeable and denote differing philosophical foundations to the inclusion of non-technical content on engineering programmes. Here, we can delineate differing conceptual approaches, broadly summarized as 1 ) interdisciplinary: programmes that allow students to study content offered across different departments 2) multidisciplinary (may also be termed pluridisciplinary or transdisciplinary): broadly where students/teaching staff incorporate non-engineering learning into the curriculum, or 3) a-disciplinary: the incorporation of content/pedagogical style that transcends traditional disciplinary boundaries, hence applicable in some way for most HE students. In the UK this is often defined as 'transferable skills'. In research that uses interdisciplinarity as a focus for empirical study it is helpful to be mindful of these differing concepts.

There is a general agreement that interdisciplinary, multidisciplinary, or holistic approaches in engineering courses are a positive step (see Barnard et al., 2012a). Cotgrave (2005) argues that a 'holistic' approach to developing design solutions, the ability to appreciate the broad range of professions within the sector and develop a wider appreciation of the context in which engineers work, is crucial (see also Richter and Paretti [2009]). A more holistic education is argued to make students better engineers in practice. However, the requirements for gaining chartered status is set by the professional accreditation bodies, which makes including interdisciplinary modules to an already packed programme of study problematic (Powell et al., 2004, see also Winberg, 2008).

The driving force for skills development in the engineering sector is linked to productivity levels, an identified skills shortage and a focus upon the skills the industry needs (Barnard et al., 2012a). Markes' (2006) review of employability skills in the UK engineering sector reveals the need for adaptability, flexibility, 
good communication skills and team work, all of which relate to the disciplinary flexibility and transferable skills of engineering students. The requirements of industry are increasingly dominant in the UK as student employability and the utility of a university degree are at the forefront of students' minds in making choices about where and what to study, especially since the introduction of tuition fees in 1998. The development of interdisciplinary engineering education based upon a broad definition of curriculum is also a product of closer relationships between universities and employers.

Other research that focuses on the benefits of interdisciplinary developments is described by Harrison et al. (2007) who argue that interdisciplinary collaboration is critical for UK engineers. It was found that some companies experienced 'skills gaps', where time and money was spent getting graduates up to speed with the requirements of the job. They argue that engineering is traditionally 'mono-disciplinary' - encouraging specialist technical knowledge and a strong identification with own discipline- at the expense of broader knowledge/skills and appreciation of other disciplines. As graduates will often go on to work in 'multi-functional' teams (in larger companies) or themselves adopt a wider spectrum of roles (in smaller companies), a mono-disciplinary approach does not adequately prepare engineers for this 'reality'. Spinks et al. (2007) note an emphasis on the multi-faceted nature of contemporary engineering work and on the need to understand the whole range of input that results in the success of a project. Thus, the widening of the experience and skills of engineers can be conceived as a response to wider changes in society and engineering organizations.

\section{Methodology}

In order to explore the nature and experience of interdisciplinary education we adopted a mixed method approach, combining curriculum analysis and interviews with students. In the UK, Civil Engineering is the third highest engineering subject area by student enrolments (following Mechanical and 
S. Barnard, T. Hassan, B. Bagilhole and A. Dainty (2013) Interdisciplinary Content, Contestations of Knowledge and Informational Transparency in Engineering Curriculum. Teaching in Higher Education, Vol. 18, Iss. 7, 2013. Available at: http://www.tandfonline.com/doi/full/10.1080/13562517.2013.836089\#

Electrical and Electronic Engineering), with 4796 students accepted onto Civil Engineering degree programmes in 2010 (UCAS, 2011). Within the broad Civil Engineering subject area there are approximately 300 programmes delivered in the UK. In order to focus our analysis of the extent of interdisciplinary content in civil engineering curriculum we concentrate upon programmes at the MEng level that are delivered at $40 \mathrm{HE}$ institutions in the UK. In order to provide a full picture we collected data on at least one MEng programme at each institution that provides MEng programmes in Civil Engineering.

The curriculum analysis was an important part of the research as this allowed a deeper understanding of what is taught, prior to interrogating students' experiences and responses to such an education via one-to-one interviews. This follows the work Bernstein (1971) who looked at the codes of framing of knowledge and how students/staff are socialised into a subject and later Bird (2001) who argues for a sociology of academic curriculum that questions what is taught and why. Bird (2001) suggests that most attention on curriculum focuses on the 'how' rather than 'what' question and therefore little is known about what is taught and how disciplines are defined and maintained. Bernstein's notion of classification is useful for thinking about what happens when you attempt to weaken the boundaries between disciplines in order to create interdisciplinarity, raising questions about power relations and the interests served in changes to academic boundaries. Ultimately educational fields can be viewed as arenas of practice and sites of contestation, conflict and struggle with regards to meaning and power (Bernstein, 1999). As Bernstein's analysis of education and knowledge brings to the fore the principles of social control and expressions of power we may look closer at the development of interdisciplinary education, in this case in engineering, and perceive that changes in $\mathrm{HE}$ reflect trends evident more widely in society.

In this research we focus on identifying interdisciplinary content in the civil engineering curriculum, 'which was broadly defined as 'non-technical'. The delivery of innovative programmes is not always easily separated from innovative pedagogy and the difficulties associated with how to define 
S. Barnard, T. Hassan, B. Bagilhole and A. Dainty (2013) Interdisciplinary Content, Contestations of Knowledge and Informational Transparency in Engineering Curriculum. Teaching in Higher Education, Vol. 18, Iss. 7, 2013. Available at: http://www.tandfonline.com/doi/full/10.1080/13562517.2013.836089\#

interdisciplinary content are raised during the research. Through curriculum analysis we can uncover the details of what is taught and begin to understand the complex interplay between differing 'modes' of learning students digest over the course of their study. Moore and Young (2001) discuss the dominance of two competing ideologies with regards to curriculum; 'neoconservative traditionalism' and 'technical instrumentalists', these kind of metanarratives amongst others may be played out in the interaction between the profession and the academy, at faculty level, between students and teachers, but also can be found in the curriculum itself - what is taught and why. These debates are also explored in the interviews with students.

Interviews were conducted with students at four different institutions in order to explore how the curriculum content is experienced and perceived. The interviewees were accessed in liaison with the staff in the academic department in which their programme was based. In total 24 interviews with students took place at $4 \mathrm{HEIs}$ - with 12 female and 12 male students. Semistructured interviews allowed an exploration of various aspects of students' decision making processes and experiences on their programme of study.

\section{Curriculum analysis}

\section{Accessing data}

Less than half of institutions looked at had detailed curriculum information freely available on their websites at that time (April-June 2010); in order to access this information to perform the curriculum analysis it was necessary to contact 24 institutions directly (39 institutions in total were looked at). This was carried out with varied success. Some institutions would not provide the curriculum information necessary to identify interdisciplinary content (see table 1).

Once the curriculum details were available the process for analysing content began by looking closely at the module titles and descriptions - does the module have a focus on non-technical education? Does the module offer a 
S. Barnard, T. Hassan, B. Bagilhole and A. Dainty (2013) Interdisciplinary Content, Contestations of Knowledge and Informational Transparency in Engineering Curriculum. Teaching in Higher Education, Vol. 18, Iss. 7, 2013. Available at: http://www.tandfonline.com/doi/full/10.1080/13562517.2013.836089\#

more contextual analysis of civil engineering? Does the module contain nonengineering content? For modules that we could answer yes, a note was made of the credit for this module and analysis was performed for overall scores and the interdisciplinary content within each year and for the whole programme.

In the context of this study interdisciplinary content was found under a variety of guises. Examples of modules that we considered added interdisciplinary content to programmes include; Economics and Structure of Industry; Philosophy; Rights and Wrongs: The Engineering Profession and Society; The Aesthetics of Design; Languages; Business and Management Studies; Teamwork and Leadership; Organisational Theory and Behaviour; Finance; Law and Contracts; Sustainable Development and the Environment; also, modules that have transferable skills as their focus - developing communication skills etc.

\section{Results}

The curriculum analysis shows that there are relatively low levels of interdisciplinary content in civil engineering curriculum in the UK. This is consistent across all years for all institutions as the mean data shows around 13-15 per cent. A more detailed look at the results shows that some institutions have a greater amount of interdisciplinary content; for example, Birmingham; Brunel; Coventry; Dundee; University College London and Warwick. In particular, we can see that the Civil Engineering programme offered at an institution such as Warwick had significantly higher levels of interdisciplinary content due to the fact that the first year programme is a general engineering programme that allows students a wider curriculum before a greater emphasis on civil engineering in later years. Institutions that offered less interdisciplinary content were; Bath; Durham; Edinburgh Napier; and Salford. The curriculum analysis differentiates between levels of interdisciplinarity by first year of programme, or second year and later, which allows for a more nuanced examination of the ways in which this kind of content is incorporated into more mainstream curriculum. For example, the 
S. Barnard, T. Hassan, B. Bagilhole and A. Dainty (2013) Interdisciplinary Content, Contestations of Knowledge and Informational Transparency in Engineering Curriculum. Teaching in Higher Education, Vol. 18, Iss. 7, 2013. Available at: http://www.tandfonline.com/doi/full/10.1080/13562517.2013.836089\#

MEng programme at Glasgow University has above average interdisciplinary content in the first year (21\%) but offers none at all for the rest of the programme, whilst Coventry University has below average content in the first year, yet incorporates much more interdisciplinary content in the later years of the programme (35\%). The analysis conducted presents an interesting starting point for a discussion about how this kind of content is included in the curriculum and how there are many different approaches in teaching what appears to be on the surface the same degree programme.

\section{Student interviews}

We conducted interviews with students that explored their decision to study civil engineering, experiences on the programme and views on what is taught. As a talking point in the interviews we produced condensed versions of their own degree curriculum and one for another institution for them to read through and discuss. This enabled the student to make comparisons between curriculum content, which turned out to be a fruitful way of gaining an insight into their opinions about what is suitable to be taught on a civil engineering programme.

Participants were asked to reflect upon the factors that impacted on their decision to study the civil engineering discipline and embark upon their programme of study. For the majority of respondents peers and family are influential with regards to decisions about where and what to study - for these civil engineering students in particular, family were cited as being generally supportive, though sometimes uninformed about what civil engineering is. Our findings reflect findings of other research that outlines the importance of familial and peer influence on higher education choice (see Breakwell et al., 1988; Reay et al., 2001; Brooks, 2003; David et al., 2003; Barnard et al., 2012b). Many of the respondents spoke about key family members who emphasise the idea that maths/sciences are 'proper' subjects, thus directly and indirectly influencing these students' decision to study an engineering subject. This reflects a general perception about suitable areas of study that does not drill down to the level of curriculum content: the programme title/ 
S. Barnard, T. Hassan, B. Bagilhole and A. Dainty (2013) Interdisciplinary Content, Contestations of Knowledge and Informational Transparency in Engineering Curriculum. Teaching in Higher Education, Vol. 18, Iss. 7, 2013. Available at: http://www.tandfonline.com/doi/full/10.1080/13562517.2013.836089\#

subject area is enough. It is the idea of what a subject is, rather than an explicit knowledge of programme content that is influential. It is presumed that a 'proper' sounding subject like civil engineering will entail a 'proper' education. One student describes how she came to be doing civil engineering;

'I think it was at A Levels and it was by absolute chance because I wanted to go into drama but I was really good at maths and physics and my teacher rang me up and said, "Are you sure you want to do this? Are you sure you don't want to go into something a bit more substantial?" So in my GCSE years I got told that engineering is probably the best thing for me to do. I wanted to do architecture initially and when I got researching engineering it took my fancy. A lot of research on the internet and then I decided that's definitely what I wanted to do and that's how I came about it'. (DF2)

Non-content based reasons given for taking a particular study programme were equally prevalent across all respondents; they include reputation of institution, location of institution (i.e. to live nearer home to keep living costs low), perception of campus, support, influence of friends and family. Previous research on student choice of HE programme has found motivations for choice to be highly based upon socio-economic background, those from working class or ethnic minorities taking particular aspects into account in their decision making (for a more detailed discussion see Reay et al, 2001; Dawes and Brown, 2005; Voigt, 2007; Davies et al., 2012). In this study, factors influencing the specialism chosen in civil engineering include; being an 'outdoors person'; having an interest in structures (but a 'proper' subject i.e. maths/science based, unlike the more 'arty' architecture); choice of A-Level subjects; and perception of good career prospects.

Various reasons emerged as influencing students' choice of programme. For some students, the choices are limited to what is available once the grades have been published; 'I went through clearing so didn't have much choice of where to go' (DM1). Most participants responded that course content was not influential in their decision to take a particular study programme. Many 
S. Barnard, T. Hassan, B. Bagilhole and A. Dainty (2013) Interdisciplinary Content, Contestations of Knowledge and Informational Transparency in Engineering Curriculum. Teaching in Higher Education, Vol. 18, Iss. 7, 2013. Available at: http://www.tandfonline.com/doi/full/10.1080/13562517.2013.836089\#

students knew they wanted to study civil engineering, but made the decision between potential programmes of study on other factors (such as university ranking, location, the opportunity to do a year in industry etc.). One response that is common amongst the respondents was a student who said that he did not look into course content, as he knew he wanted to do civil engineering (DM2). Another respondent commented that; 'I wasn't really sure what the university course would contain and we didn't get much information on it' (AF3). A few respondents had previous knowledge of course content as they had an older sibling or friend doing the course, but on the whole it seems the students lack knowledge of what they will study until they are studying it.

In terms of students' experiences of the curriculum, they acknowledged the MEng Civil Engineering as a 'broad' education that highlights the importance of knowledge of other engineering disciplines, the need to include transferable skills and group project work to reflect professional working practices. A step beyond the perception of civil engineering as a relatively 'open' discipline is the inclusion of interdisciplinary content: what did students think about this? In general both male and female students reported being initially surprised by the presence of non-technical content (e.g. management) however most respondents appreciated the non-technical content later in their degree, particularly those that undertook an industrial placement. One respondent commented on a business and management module; 'they've definitely given me quite an insight into actually how the business and the other side of construction works, which was something that on my year out was picked up as a weakness of mine' (AM3). Another respondent questions the inclusion of interdisciplinary content on his programme;

'For me, I can't understand why that's there as part of the civil's module. And then even a Modern Foreign Language - okay, sometimes you get stuff with a language extra. Then Rights and Wrongs of the Engineering Profession Society - yeah, that seems relevant as a first year module. But then Introduction to Ancient Philosophy - to me, I don't think it's specific to a civil engineering course' (DM1). 
S. Barnard, T. Hassan, B. Bagilhole and A. Dainty (2013) Interdisciplinary Content, Contestations of Knowledge and Informational Transparency in Engineering Curriculum. Teaching in Higher Education, Vol. 18, Iss. 7, 2013. Available at: http://www.tandfonline.com/doi/full/10.1080/13562517.2013.836089\#

However, some respondents noted a change in perceptions towards interdisciplinary content over time, with students nearing the end of the MEng reporting a greater understanding of the necessity of this kind of education to prepare for the world of work. As one respondent states;

'I didn't really realize there would be so much construction management, project management, finance management. And to me, well at the beginning I didn't think that was civil engineering, and obviously I am in my last year now and I realize you do need to understand it. But at the beginning I was a bit like 'whoa! This isn't civil engineering" (AF2)

An interesting finding was that some found the non-technical modules more difficult as they were out of their 'comfort zone'. As well as a discussion of the programme on which respondents were studying they were asked to look over a summary of an alternative curriculum from another institution. Some respondents questioned the narrower curriculum and prefer the broader curriculum;

'I think our programme tends to make you more sellable to other people as well, you could go into a different industry and you would have transferable skills. Whereas with the one from the other university tends to be more technical' (AF3)

Conversely, some questioned the technical ability of those students on the more interdisciplinary programme suggesting that the inclusion of interdisciplinary content is at the expense of important technical education. This view is mirrored in Alpay's (2012) discussion of the development of general engineering programmes in the UK, which highlights that 'some institutions may view direct specialisation as a competitive edge or niche over other equivalent (e.g. research-intensive) institutions offering general engineering' (Alpay, 2012: 10). Further, in our study many students stated that 
S. Barnard, T. Hassan, B. Bagilhole and A. Dainty (2013) Interdisciplinary Content, Contestations of Knowledge and Informational Transparency in Engineering Curriculum. Teaching in Higher Education, Vol. 18, Iss. 7, 2013. Available at: http://www.tandfonline.com/doi/full/10.1080/13562517.2013.836089\#

they preferred the more technical programme. Overall, we found a mixed picture with regards to student perceptions of interdisciplinary content.

\section{Discussion: contestations of knowledge and informational transparency}

The context of the institutions that provide engineering $\mathrm{HE}$ and the influence of industry on such programmes may constrain change in the curriculum when tied closely with 'traditional' cultures and norms, even in universities where interdisciplinarity is a specified goal (Pharo et al., 2012). Bagilhole and Goode (1998) found that in male-dominated disciplines, such as engineering, a 'narrow' definition of the term 'curriculum' was predominantly in use. This features strongly defined appropriate discipline content and an unproblematic body of knowledge (McKenna and Yalvac, 2007). A recent study by Alpay (2012) on student attraction to flexibility and breadth in engineering curriculum found that a general engineering programme that offers the opportunity to specialise later in the degree programme to be a good option for students who were considering doing a degree. In the same study it was found that students indicated the importance of non-technical content; 'four common items appeared amongst the top six rankings: leadership; teamwork; business skills; self-awareness and personal development' (Alpay, 2012: 9). Thus, the tradition of engineering that focuses upon 'technical' skills is in conflict, not only with people who do not identify with a technical discipline, but also with prospective students themselves and the modern take on the multidimensional engineering professional.

The difficulties found in accessing curriculum information and the students' lack of knowledge of curriculum prior to study demonstrates that there is a need for greater transparency that goes beyond superficial information, which would allow future students to learn more about the curriculum and find a programme of study that matches their interests. KIS present greater possibilities for this to happen, however, proposals for KIS do not include detailed information on programme content instead concentrating on easily 
S. Barnard, T. Hassan, B. Bagilhole and A. Dainty (2013) Interdisciplinary Content, Contestations of Knowledge and Informational Transparency in Engineering Curriculum. Teaching in Higher Education, Vol. 18, Iss. 7, 2013. Available at: http://www.tandfonline.com/doi/full/10.1080/13562517.2013.836089\#

comparable and visual information; for example figures on contact time and employability.

It is important to acknowledge the potential for greater information available on curriculum content to be counterproductive to initiatives that develop interdisciplinary education - as students who are set on studying, civil engineering for example, do not necessarily want interdisciplinary content. The idea of greater openness and availability of information, follows general trends in $\mathrm{HE}$ in the UK around the publication of performance indicators that are aimed at providing prospective students information from which they are able to make choices about where and what to study, but these tend to be focused on delivery of education and outcomes rather than the content of degree programmes: a focus on the 'how' and 'outcomes' of learning, rather than the 'what' question. Respondents in this research demonstrated a significant lack of detailed knowledge about the content of the programme of study prior to enrolment, but also ambivalence towards non-technical content: this leads to questions about how far universities may innovate curricula when student (and family) expectations are firmly rooted at the heart of the traditional discipline. As Strathern (2000) notes there may be unintended consequences to greater transparency and the use of performance indicators in individual and organizational decision making.

\section{Conclusions}

This article outlined our findings on the prevalence of interdisciplinary curriculum in civil engineering in the UK and the views and experiences of students with regards to this kind of education. We found that universities currently operate a varied approach to transparency regarding curriculum with less than half of institutions making detailed curriculum information freely available on their websites. The introduction of KIS provides an opportunity for more easily accessable information on curricula, but mainly focuses on mode of delivery, services to students and outcomes. Taking into account Strathern (2000) and others' reservations about increasing transparency in HE, we 
suggest that if students do not have the opportunity for learning more about what they will be expected to study (not just the 'how' but the 'what' question) we can assume that curriculum is something that informs experience, but not decisions about which programme of study to embark upon. Moves towards interdisciplinary education, not only in civil engineering, but across the engineering faculty and beyond, may or may not be welcomed by students wanting a purely technical education, and may come as a surprise to those not previously informed of curriculum content. The boundaries of what is considered to be interdisciplinary will differ according to subject area and as such offers an interesting window into sites of struggle for meaning and power in academic pedagogy (Bernstein, 1970). The research presented here offers an interesting starting point for a discussion about how this kind of content is developed, communicated to and experienced by students.

\section{Acknowledgement}

The research leading to these results has received funding from [removed to maintain anonymity]. The authors would like to thank the interview participants for their input and the time of departmental staff at the four institutions who helped to promote the project to their students. The authors would also like to thanks anonymous reviewers for their comments on a draft of the article.

\section{References}

Alpay, E. (2012): Student attraction to engineering through flexibility and breadth in the curriculum, European Journal of Engineering Education, 2012: 1-19

Bagilhole, B. and Goode, J. (1998) The 'Gender Dimension' of both the 'Narrow' and 'Broad' Curriculum in UK Higher Education: Do women lose out in both? Gender and Education, 10 (4): 445-458.

Barnard, S., Bagilhole, B., Dainty, A. and Hassan, T., (2012a) Women, engineering and Higher Education in the UK: Trends in Participation and Curriculum Development. In: A. Béraud, A.-S. Godfroy, J. Michel, eds. Gender and Interdisciplinary Education for Engineers. Does Interdisciplinary Education improve the gender balance and attract more young people in Engineering and Technology higher education? 
Proceedings of the GIEE HELENA Conference, Paris June 23-24 2011. Rotterdam: Sense.

Barnard, S., T. Hassan, B. Bagilhole and A. Dainty (2012b) "They're not girly girls': an exploration of quantitative and qualitative data on engineering and gender in Higher Education' in the European Journal of Engineering Education, available online $24^{\text {th }}$ February at http://www.tandfonline.com/doi/abs/10.1080/03043797.2012.661702

BBC (2011) 'Students to get best-buy facts and consumer rights', $24^{\text {th }}$ June 2011, available at; http://www.bbc.co.uk/news/education-13874483

Bernstein, B. (1971) On the classification and framing of educational knowledge, in: M.F.D. Young (Ed.) Knowledge and Control: new directions for the sociology of education (London, Collier Macmillan).

Bernstein, B. (1999) 'Vertical and Horizontal Discourse: An essay', British Journal of Sociology of Education, Volume 20, Issue 2: 157-173.

Bird, Elizabeth (2001): Disciplining the Interdisciplinary: Radicalism and the academic curriculum, British Journal of Sociology of Education, 22:4, 463-478

Borrego, M. and S. Cutler (2010) Constructive Alignment of Interdisciplinary Graduate Curriculum in Engineering and Science: An Analysis of Successful IGERT Proposals, Journal of Engineering Education, 99:4, 355-69.

Breakwell, G. M., Fife-Schaw, C. and Devereux, J. (1988), Parental influence and teenagers' motivation to train for technological jobs. Journal of Occupational Psychology, 61: 79-88.

Brooks, Rachel (2003): Young People's Higher Education Choices: The role of family and friends, British Journal of Sociology of Education, 24:3, 283-297

Buchanan, R. A. (1989) The Engineers: A History of the Engineering Profession in Britain, 1750-1914. Jessica Kingsley Publishers: London.

Cotgrave, A. (2005) Tuning the Undergraduate Construction Curriculum: Embedding Health, Safety and Environmental Issues in Order to Improve Employability, CEBE Transactions, Vol. 2, Issue 1, April 2005, pp 28-43 (16).

David, M. E. S. J. Ball , J. Davies \& D. Reay (2003): Gender Issues in Parental Involvement in Student Choices of Higher Education, Gender and Education, 15:1, 21-36

Davies, P. (2012): Can Governments Improve Higher Education 
S. Barnard, T. Hassan, B. Bagilhole and A. Dainty (2013) Interdisciplinary Content, Contestations of Knowledge and Informational Transparency in Engineering Curriculum. Teaching in Higher Education, Vol. 18, Iss. 7, 2013. Available at: http://www.tandfonline.com/doi/full/10.1080/13562517.2013.836089\#

Through 'Informing Choice'?, British Journal of Educational Studies, 60:3, 261-276

Davies , P. J. Mangan , A. Hughes \& K. Slack (2012): Labour market motivation and undergraduates' choice of degree subject, British Educational Research Journal, DOI:10.1080/01411926.2011.646239

Dawes, P. L. \& J. Brown (2005): The Composition of Consideration and Choice Sets in Undergraduate University Choice: An Exploratory Study, Journal of Marketing for Higher Education, 14:2, 37-59

Gregory, Malcolm S. (1971) History and Development of Engineering. Longman: London.

Harrison, G.P., Macpherson, D.E., and Williams, D.A., (2007) Promoting interdisciplinarity in engineering teaching. European Journal of Engineering Education, 32 (3), 285-293.

HEFCE (2012a) 'Key Information Sets', available at; http://www.hefce.ac.uk/whatwedo/tt/publicinfo/kis/

HEFCE (2012b) 'PIs: An Introduction', available at; http://www.hesa.ac.uk/index.php?option=com content\&task=view\&id=2073\&lt $\underline{\text { emid }=141}$

Ivins, J.R. (1997) Interdisciplinary project work: practice makes perfect? IEEE Trans. Educ., 1997, 40(3), 179-183.

Lueddeke, G. (2010) 'Curriculum matters: building capacity for strategic change in UK higher education', Int. J. Strategic Change Management, Vol. 2, No. 1, pp.18-31.

Markes, I. (2006) A review of literature on employability skill needs in engineering. European Journal of Engineering Education, 31 (6), 637650.

McKenna, Ann F. \& Bugrahan Yalvac (2007): Characterizing engineering faculty's teaching approaches, Teaching in Higher Education, 12:3, $405-418$

Moore, Rob \& Michael Young (2001): Knowledge and the Curriculum in the Sociology of Education: Towards a reconceptualisation, British Journal of Sociology of Education, 22:4, 445-461

New Civil Engineer (2009) 'Engineering education has come a long way over a long time' New Civil Engineer 21 May 2009. Available at; http://www.nce.co.uk/news/ice/engineering-education-has-come-along-way-over-a-long-time/5202408.article

Pharo, E.J., A. Davison, K. Warr, M. Nursey-Bray, K. Beswick, E. Wapstra 
S. Barnard, T. Hassan, B. Bagilhole and A. Dainty (2013) Interdisciplinary Content, Contestations of Knowledge and Informational Transparency in Engineering Curriculum. Teaching in Higher Education, Vol. 18, Iss. 7, 2013. Available at: http://www.tandfonline.com/doi/full/10.1080/13562517.2013.836089\#

\& C. Jones (2012): Can teacher collaboration overcome barriers to interdisciplinary learning in a disciplinary university? A case study using climate change, Teaching in Higher Education, available online $29^{\text {th }}$ February 2012.

Powell, A., Bagilhole, B., Dainty, A. and Neale, R. (2004) Does the Engineering Culture in UK Higher Education Advance Women's Careers. Equal Opportunities International, 23 (7/8): 21-38.

Pugh, G., G. Coates and N. Adnett (2005) 'Performance Indicators and Widening Participation in UK Higher Education', Higher Education Quarterly, Volume 59, No. 1, January 2005, pp 19-39

Reay, D., J. Davies, M. David and S.J. Ball (2001) 'Choices of Degree or Degrees of Choice? Class, 'Race' and the Higher Education Choice Process', Sociology 35: 855

Severn, R. T. (2009) The Development of the Faculty of Engineering At The University of Bristol 1909-2009: A History To Mark Its Centenary. Available at; http://www.ima.org.uk/news/rt_severn.html

Skates, G. W. (2003) 'Interdisciplinary project working in engineering education', European Journal of Engineering Education, 28:2,187 201.

Spinks, N., Silburn, N.L.J., and Birchall, D.W. (2007) Making it all work: the engineering graduate of the future, a UK perspective. European Journal of Engineering Education, 32 (3), 325-335.

Strathern, M. (2000): The Tyranny of Transparency, British Educational Research Journal, 26:3, 309-321

Tsoukas, H. (1997) The tyranny of light: the temptations and paradoxes of the information society, Futures, 29, pp. 827-843.

UCAS (2011) Online statistics on student applications and acceptances by subject. Available at; www.ucas.ac.uk

Voigt, K. (2007) 'Individual choice and unequal participation in higher education', Theory and Research in Education 2007 5: 87-112.

Winberg, C. (2008) Teaching engineering/engineering teaching: interdisciplinary collaboration and the construction of academic identities, Teaching in Higher Education, 13:3, 353-367 